\title{
COVID-19 E USO DE PLATAFORMAS DIGITAIS: REVERBERAÇÕES DA SALA DE AULA DO ESPAÇO FÍSICO PARA O VIRTUAL
}

\author{
COVID-19 Y USO DE PLATAFORMAS DIGITALES: REVERBERACIONES EN EL \\ AULA DESDE EL ESPACIO FÍSICO HASTA LO VIRTUAL
}

\author{
COVID-19 AND USE OF DIGITAL PLATFORMS: CLASSROOM REVERBERATIONS \\ FROM PHYSICAL TO VIRTUAL SPACE
}

\author{
Caique Fernando da Silva FISTAROL ${ }^{1}$ \\ Éderson Luís SILVEIRA ${ }^{2}$ \\ Adriana FISCHER ${ }^{3}$
}

RESUMO: Este trabalho busca analisar pronunciamentos enunciativos extraídos de questionários semiestruturados realizados por e-mail, em meio à pandemia do coronavírus, com 13 professores de língua inglesa da Rede Pública Municipal de Ensino de Blumenau, que trabalharam em modo remoto durante o ano letivo de 2020. Desse modo, busca-se mobilizar os conceitos bakhtinianos de dialogismo e de discurso no âmbito da análise efetuada. Para isso, percorrer-se-ão, teoricamente, contribuições pontuais dos estudos do Círculo de Bakhtin para os Estudos da Linguagem. Vale destacar que, na análise efetuada, focaremos na devolutiva dos docentes acerca da experiência de formação durante a licenciatura acerca do uso de tecnologias digitais no âmbito educacional. Conclui-se que os sujeitos discursivos são singulares, intercambiáveis e o enunciado concreto se articula a um ato responsável e responsivo, que reitera a inter-relação entre enunciados e o dialogismo das instâncias de interação verbal.

PALAVRAS-CHAVE: Pandemia. Práticas discursivas. Dialogismo. Interação verbal.

RESUMEN: Este trabajo tiene como objetivo analizar pronunciamientos enunciantes extraídos de cuestionarios semiestructurados realizados por correo electrónico, en medio de la pandemia de coronavirus, con 13 profesores de habla inglesa del municipio de Blumenau, que trabajaron a distancia durante el año escolar 2020. Por lo tanto, busca movilizar los conceptos bakhtinianos de diálogo y discurso en el contexto del análisis realizado. Para ello, teóricamente, se realizarán contribuciones específicas de los estudios del Círculo de Bakhtin para estudios lingüísticos. Cabe mencionar que, en el análisis realizada, nos centraremos en

\footnotetext{
${ }^{1}$ Secretaria Municipal de Educação (SME), Blumenau - SC - Brasil. Professor de Língua Inglesa na Rede Municipal de Ensino, Coordenador da Educação Bilíngue e de Língua Inglesa. Mestrado em Educação (FURB). ORCID: https://orcid.org/0000-0001-7650-7324.E-mail: cfersf@gmail.com

${ }^{2}$ Universidade Federal de Santa Catarina (UFSC), Florianópolis - SC - Brasil. Doutor pelo Programa de PósGraduação em Linguística. Membro-Pesquisador do Grupo de Pesquisa Formação de Professores de Línguas e Literatura - FORPROLL/CNPq e do GESTAR/CNPq. ORCID: https://orcid.org/0000-0002-8483-4656. E-mail: ediliteratus@gmail.com

${ }^{3}$ Fundação Universidade Regional de Blumenau (FURB), Blumenau - SC - Brasil. Professora Adjunta do Centro de Ciências da Educação, Artes e Letras (Departamento de Letras) e do Programa de Pós-Graduação em Educação (Mestrado e Doutorado). Doutorado em Linguística (UFSC). ORCID: https://orcid.org/0000-00019787-2814. E-mail: adrfischer@furb.br
} 
la evolución del profesorado sobre la experiencia formativa durante el grado sobre el uso de herramientas de tecnologías digitales en el ámbito educativo. Se concluye que los temas discursivos son singulares, intercambiables y la expresión concreta se articula a un acto responsable y receptivo, que reitera la interrelación entre las expresiones y el dialogismo de los casos de interacción verbal.

PALABRAS CLAVE: Pandemia. Prácticas discursivas. Dialogismo. Interacción verbal.

ABSTRACT: This paper aims to analyze enunciative pronouncements extracted from semistructured questionnaires conducted by e-mail, amid the coronavirus pandemic, with 13 English-speaking teachers from the municipality of Blumenau, who worked remotely during the 2020 school year. Thus, it seeks to mobilize the Bakhtinian concepts of dialogism and discourse in the context of the analysis performed. For this, theoretically, specific contributions from the studies of the Bakhtin Circle for Language Studies will be made. It is worth mentioning that, in the analysis performed, we will focus on the evolution of teachers about the training experience during the degree about the use of digital technologies tools in the educational scope. It is concluded that the discursive subjects are singular, interchangeable and the concrete utterance is articulated to a responsible and responsive act, which reiterates the interrelationship between utterances and the dialogism of the instances of verbal interaction.

KEYWORDS: Pandemic. Discursive practices. Dialogism. Verbal interaction.

\section{Introduzindo o percurso}

Uma das principais preocupações do Círculo de Bakhtin com a linguística de seu tempo foi mostrar de que forma a historicidade e singularidade dos sujeitos e experiências intercambiáveis incide sobre as relações entre linguagem e realidade social. Nesse ínterim, a comunicação verbal não pode ser separada das situações de existência da vida concreta. A dialogicidade está presente nesse escopo de teorizações, em que todo enunciado se dá sempre na relação entre indivíduos, em contexto social e historicamente situado. Ao pensar no âmbito das condições de enunciação concreta, a palavra pode então ser vista não apenas como signo, mas como instrumento semiótico das relações sociais no âmbito da interação tecida entre indivíduos. Não é à toa que Voloshinov (2017), que também desenvolveu estudos no âmbito do chamado Círculo de Bakhtin, afirma que o signo linguístico é marcado pelo horizonte social de uma época e de um grupo social determinado. Por isso é corrente afirmar que todo enunciado é situado histórica e socialmente, e não pode ser pensado como sendo apartado das relações sociais.

Em relação às condições concretas de enunciação temos uma pandemia que fez com que escolas no mundo todo interrompessem as aulas presenciais e migrassem, sem haver 
tempo para se preparar para tal mudança, para um modelo de aulas emergenciais remotas, mediadas pelo uso de plataformas digitais. Não apenas as escolas, mas também famílias inteiras tiveram que se adequar às transformações escolares. Só que os impactos são tão distintos quanto são abissais as desigualdades que imperam na sociedade. Antonio Gois (2020) menciona três dimensões principais a ser consideradas no Brasil: os impactos dessa migração para o ensino remoto; o papel dos pais na educação dos filhos e o agravamento das desigualdades.

\begin{abstract}
Num cenário ideal, as tecnologias seriam testadas e mapeadas, conteúdos adaptados para outros formatos, professores receberiam treinamento, e alunos e famílias teriam tempo para se adaptar à nova rotina. Mas nada disso foi possível.

Entre paralisar por completo todas as atividades de aprendizagem até o retorno das aulas presenciais ou tentar achar meios para manter os estudantes minimamente engajados, a escolha da maioria dos sistemas educacionais do planeta foi pela segunda opção. Era a mais sensata, mas não isenta de prejuízos (GOIS, 2020, p. 108).
\end{abstract}

Já havia, antes da pandemia, um debate controverso sobre o uso de tecnologias digitais no campo educacional. Mas, é preciso alertar que, para início de discussão, tal abordagem não pode ser pensada como sendo dicotômica, segundo a qual se deva posicionar contra ou a favor. A realidade é bem mais complexa. É preciso pensar que dificuldades e limitações o ensino remoto encontra em um país no qual um quarto da população, com 10 anos ou mais de idade, ainda não tem acesso à internet (cf. IBGE, 2020) ${ }^{4}$. O dado mencionado se refere ao fato de que 45,9 milhões de brasileiros não tinham acesso à internet em 2018. O levantamento foi feito no quarto trimestre de 2018 por meio da Pesquisa Nacional por Amostra de Domicílios (PNAD) e foi divulgado no primeiro semestre de 2020 (IBGE, 2020).

É importante notar que dos 45,9 milhões de brasileiros que não acessam a internet, 32, 2 milhões reside na zona urbana e 13,7 milhões reside na zona rural. A maior parte das pessoas que não acessa a internet vive no Sudeste - que é onde está concentrada a maior parte da população nacional -, mas as regiões Norte e Nordeste são as que mais apresentaram percentual em relação à população local: do total de habitantes dessas regiões, $36 \%$ e 35,3\% não acessavam a internet. No Centro-Oeste, a porcentagem é de $18,5 \%$, no Sudeste é de $18,9 \%$ e de $21,8 \%$ na região Sul. Por que é importante mencionar isso? Porque metade dos brasileiros sobrevive com uma renda de R $\$ 438$ mensais. Significa que quase 105 milhões de brasileiros vivem com menos de R\$15 por dia, segundo os dados do IBGE na Pesquisa Nacional por Amostra de Domicílios Contínua: Rendimento de todas as fontes 2019.

${ }^{4}$ Conforme mencionado anteriormente, o último IBGE, de 2019, foi divulgado em abril de 2020. 
Como estamos falando em situações concretas de enunciação, em relação ao contexto dos excertos que serão analisados mais adiante, é preciso considerar a história do cenário temporal em que os enunciados foram produzidos. Se o acesso às tecnologias digitais é desigual, ele não deixa de afetar um contingente enorme de indivíduos no planeta inteiro. No Brasil, por exemplo, o acesso à internet, na maior parte das famílias, se dá via telefone celular. Segundo a Pesquisa Nacional por Amostra de Domicílios Contínua: Tecnologia da Informação e Comunicação (IBGE, 2020), 79,3\% dos brasileiros com 10 anos ou mais têm aparelhos celulares para uso pessoal, com ou sem internet. Os $28 \%$ de brasileiros que não têm celular afirmam que é caro; $24,2 \%$ afirmaram que falta interesse em obter o aparelho, 19,8\% não sabem usar e 16,6\% afirmaram que costumam usar o aparelho de outra pessoa. Já o uso de computadores caiu para $50,7 \%$ e de tablets para $12 \%$.

É importante mencionar esses elementos, pois, desde longa data, inúmeros estudos apontam que o nível socioeconômico dos pais afeta o desempenho de muitos estudantes mundo afora. Só para se ter um exemplo, na década de 1960, o sociólogo estadunidense Coleman et al. (1966) identificaram tal fato como uma das mais sólidas evidências do campo de avaliação educacional. Assim, as condições socioeconômicas impactam o desenvolvimento da aprendizagem. Por isso as escolas públicas são tão importantes: quanto mais desenvolvido é um país no âmbito educacional, mais equanimidade há na distribuição de oportunidades de escolarização e formação.

Mas nem tudo está perdido, pois, mesmo em contextos vulneráveis, as famílias podem fazer a diferença na vida de crianças e de adolescentes. Pode ser mencionado, também, um estudo do prêmio Nobel de Economia James Heckman et al. (2010) que defende o impacto duradouro de políticas de primeira infância, somado à orientação às famílias e atendimento de qualidade desde a pré-escola. A pesquisa de Ribeiro e Vóvio (2017) analisa resultados de pesquisas sobre a vulnerabilidade social em duas metrópoles brasileiras, no que diz respeito à influência da desigualdade socioeconômica na produção da desigualdade escolar. Mais recentemente, no Brasil, o estudo de Bartholo et al (2020), vinculado a um grupo de pesquisas da UFRJ, mostra como ações familiares de inserção de livros, contação de histórias, incentivo à leitura e atividades lúdicas entre pais e filhos podem produzir frutos positivos mesmo em lares de alta vulnerabilidade social.

Tudo isso para dizer que a escola não é a única responsável pela formação educacional de crianças e adolescentes. Esse argumento, apesar de parecer óbvio, na prática pode passar despercebido ou ser negligenciado, principalmente quando famílias inteiras não acompanham a vida escolar de seus filhos e direcionam a professores a tarefa de educar (que está para além 
das instâncias de ensino e de aprendizagem). Como ficam, então, os professores em meio a essa pandemia?

\section{A análise dialógica do discurso: relações entre enunciados e sujeitos}

A teoria que utilizamos neste trabalho, como referencial teórico, é a análise dialógica do discurso. No âmbito dos estudos do Círculo de Bakhtin, todo signo é ideológico, o que significa que a ideologia permeia as relações linguageiras exercidas no meio social que os sujeitos habitam e coadunam. Por isso, os bakhtinianos vão falar em esferas da comunicação humana, porque elas podem ser muitas e, também, vão falar em responsividade, já que todo enunciado é responsivo ativo (VOLÓCHINOV, 2017).

O método, como foi denominado por Paula, Figueiredo e Paula (2011) é o dialéticodialógico, pois todos os enunciados estão inter-relacionados, assim como o corpus, ao ser analisado sob a vertente dialógica, produz um cotejo - relação permanente com outros discursos, que respondem ou são respondidos no elo da cadeia discursiva. As obras referenciadas possuem relação entre si e com outros textos, e com outros conceitos e áreas das quais advém e dialogam. Não existe, discursivamente falando, a busca por uma origem ou enunciado primeiro que teria existido antes dos demais. Por isso, a concepção de discurso está relacionada com o conceito de dialogismo.

$\mathrm{Na}$ análise dialógica do discurso, o sujeito não é fonte do dizer e é um ser social, que existe e é constituído na relação com o outro. Assim, o enunciado é visto na forma de um diálogo porque todo enunciado é dialógico, mantém relação com outros enunciados. Numa análise dialógica, não se busca a verdade, pois ela não existe. O que há são efeitos de verdade, pois todo o signo é ideológico e carrega valorações sobre os objetos que são nomeados ou sobre seres e instâncias que são tomados como objeto de discurso (VOLÓCHINOV, 2017). Desse modo, cada sujeito é intercambiável e está associado a uma historicidade que, mesmo que esteja relacionada ao contexto de vivência de outros sujeitos, o torna singular e único. Tal determinação se dá por causa dos contextos de interação específicos. Por isso, o enunciado é unidade real da comunicação discursiva e as esferas da atividade humana estão relacionadas aos usos efetivos da língua que ocorre por meio da construção de enunciados concretos. 


\section{Situando o corpus e o contexto da pesquisa}

Primeiro, torna-se necessário situar o município de Blumenau. De acordo com o IBGE 2019, divulgado em 2020, Blumenau tem 361.855 habitantes e um PIB de 16 milhões de reais. É a terceira cidade mais populosa do estado de Santa Catarina, depois de Joinville e de Florianópolis, respectivamente. O município pertence à região do Médio Vale do Itajaí, em Santa Catarina, no Sul do Brasil. Esta região tem 808.502 habitantes e é composta por 14 municípios e, nesse âmbito, Blumenau é o município mais populoso, enquanto Dom Pedrinho é a cidade com menor população (4.115 habitantes). É importante mencionar que a população urbana de Blumenau é composta de 241.943 pessoas $(92,41 \%)$ e a população rural de 19.865 pessoas (7,59\%), estando, portanto, a maior parte na zona urbana. Segundo o Programa das Nações Unidas para o Desenvolvimento (PNUD, 2021), o IDH geral da cidade é de 0,855, considerado alto, no ranking de desenvolvimento humano de Santa Catarina, ocupando a $5^{\mathrm{a}}$ posição no estado e $19^{\mathrm{a}}$ no cenário brasileiro.

Em relação à renda per capita, pode-se afirmar que tem um Índice de Desenvolvimento Humano (IDH) de 0,797 (médio); o PIB per capita é de 45.934,42 reais. A indústria têxtil é a principal atividade econômica da cidade por causa da presença de fabricantes que foram fundados no século XIX, como a Hering e a Karsten. Mas o município também tem se destacado como polo de tecnologia da informação (T.I.), o que ocasionou a diversificação da economia do lugar. A área de T. I. já é maior fonte de arrecadação de Imposto Sobre Serviços de Qualquer Natureza (I.S.S.), existindo desde 1970 quando cerca de 10 empresas se reuniram para estabelecer uma central de serviços tecnológicos, intitulado Centro Eletrônico da Indústria Têxtil - CETIL (cf. SINTEX, 2018).

Também há o comércio, a prestação de serviços e o segmento do turismo de eventos, por causa de feiras de projeção internacional, que ocorrem na Vila Germânica. Para se ter uma ideia da presença econômica da cidade, em 2017, ela chegou a exportar produtos em um montante equivalente a 430.647 .320 dólares, figurando como 5,06\% das exportações do estado $^{5}$. Acerca do aspecto educacional, pode ser mencionado que a taxa de escolarização de 06 a 14 anos de idade no município é de 97\% (IBGE, 2020). A Rede Pública Municipal de Blumenau conta com 13.791 matrículas na Educação Infantil e 21.346 matrículas no Ensino Fundamental, 1.596 docentes na Educação Infantil e 1596 docentes no Ensino Fundamental. A Rede Pública Municipal de Ensino de Blumenau conta, ainda, com 79 Centros de Educação Infantil (CEIs) e 46 Escolas. Em relação às formações continuadas ofertadas pela Prefeitura

5 Disponível em: https://drive.google.com/file/d/0B0qbkUSL-vfjUkFueFM1eW96aW8/view. Acesso em: 23 nov. 2020. 
Municipal de Educação, sobretudo pela Secretaria Municipal de Educação, são ofertados dois cursos: 1. Informática Básica - 20h; 2. Google Sala de Aula e aplicativos do Google - 40h.

Tais cursos são ofertados, semestralmente, por adesão dos profissionais da Educação que tiverem interesse. Esses profissionais podem participar na sua Hora-Atividade Extraclasse, ou ainda no período noturno. Tais cursos são ofertados, via edital, desde o ano de 2016 e contam, em média, com a participação de 50 profissionais por ano. Devido ao ano atípico, de 2020, por causa da situação pandêmica vivenciada, foram ofertados cursos referentes ao uso do Google Sala de aula e de aplicativos do Google, com número de vagas estabelecidas para cada Centro de Educação Infantil e Escola da Rede Municipal de Ensino. Foram priorizadas, por exemplo, as Instituições de Ensino que não possuíam profissional de informática para auxiliar nesses trâmites. Só para que se tenha uma ideia da abrangência e do alcance, os cursos ofertados no ano passado totalizaram a participação de 420 profissionais da Educação. Além disso, pode ser mencionado, também, que o setor CAPACITA - setor de formação a todos os profissionais da Prefeitura Municipal de Blumenau - ofertou um curso sobre Ensino Híbrido a todos que tivessem interesse. Essa oferta ocorreu pela primeira vez, via edital de adesão, no segundo semestre de 2020.

Atualmente, no campo da Educação, Blumenau conta com 23 (vinte e três) professores de Língua Inglesa na rede municipal de ensino. Desses, 13 (treze) foram entrevistados no final de 2020 via utilização de um questionário semiestruturado realizado por e-mail ${ }^{6}$. A ferramenta utilizada se mostrou segura e responsável em meio a um período conturbado e turbulento em que vivemos, ocasionado pela expansão da pandemia da COVID-19, o que requer que seja mantido o distanciamento social, visando minimizar a proliferação do coronavírus. No questionário, há duas partes: na primeira, por meio de questões majoritariamente compostas de alternativas de múltipla escolha, os docentes deviam assinalar idade, aspectos formativos, gênero, se a formação superior inicial foi presencial ou à distância, instâncias referentes à atuação profissional e à formação continuada.

Ao final da primeira parte é questionado se, considerando os questionamentos efetuados anteriormente, haveria interesse de participar de um questionário para responder e refletir algumas questões sobre Covid-19 e o uso de plataformas virtuais no âmbito educacional. Caso a resposta seja afirmativa, é necessário que sejam assinalados o nome completo, o contato para posterior devolutiva da pesquisa realizada e a data do preenchimento. A segunda parte é composta de questões de respostas abertas e então é

${ }^{6}$ Trata-se de um instrumento próprio de pesquisa direcionada no meio científico e aplicado pelos autores deste trabalho. 
questionado como se deu a formação inicial em relação ao uso de tecnologias digitais, se há momentos na escola para discutir a formação entre os professores, se há infraestrutura adequada para que as tecnologias de informação e comunicação possam ser utilizadas como um recurso pedagógico, como está sendo a adaptação fora do espaço escolar, condições para o planejamento das aulas, limites e possibilidades diante da necessidade do ensino remoto, e qual o papel que as tecnologias de informação e comunicação podem exercer no movimento de ensinar e aprender.

Para preservar a privacidade dos professores entrevistados, serão nomeados apenas por meio de uma letra, para fins de especificação. Ex: professora AL, professor JT, etc. Um detalhe que chamou atenção é que apenas duas professoras tiveram formação acadêmica de licenciatura à distância (Professoras $\mathrm{CN}$ e KD). Entre professores e professoras entrevistados, apenas um docente teve formação acadêmica de licenciatura na modalidade semipresencial (Professor JT). Todos os demais tiveram formação somente presencial. É importante mencionar isso, pois, ao nos referirmos a experiências no âmbito do ensino remoto, tal fato corrobora para um estranhamento constitutivo das experiências de formação acadêmica inicial em nível de graduação. Não se trata de hierarquizar modos de funcionamento do ensino presencial, semipresencial ou à distância, mas de atentar para a familiaridade com essa ou aquela modalidade de ensino, por exemplo. Vale destacar que, para esta análise, focaremos apenas na devolutiva dos docentes para uma pergunta. Trata-se da primeira pergunta do questionário semiestruturado, que indagou sobre a experiência de formação durante a licenciatura acerca do uso de tecnologias digitais no âmbito educacional. Da teoria bakhtiniana, consideraremos os conceitos de enunciado, signo ideológico e dialogismo.

\section{Análise dos pronunciamentos enunciativos: $o$ dialogismo nas relações educacionais}

Considerando o número de entrevistados, reiteraremos, para análise, excertos ou paráfrases de respostas mais recorrentes no corpus em análise. Nesse âmbito, por exemplo, a Professora AL mencionou que teve uma disciplina sobre Informática cujo nome ela não se recorda, somente lembra que a didática do docente era péssima, porque ele tinha "muitos alunos para um só professor atender". Esta afirmação se situa em meio a este depoimento: "Tive uma disciplina (não lembro o nome) sobre informática. Muitos alunos para um professor só atender. E ele não tinha nenhuma didática (e vontade) para nos auxiliar. Foi péssima!!!" (Professora AL, 2020). 
Bakhtinianamente, é importante mencionar que o ser humano não apenas se constrói como objeto de estudo por meio de textos como também é conhecido por meio deles. Dessa forma, pontos de vista diferentes constroem objetos diferentes (BARROS, 2003). Uma questão que é ímpar nos estudos do Círculo de Bakhtin é a questão da alteridade. Isso porque o sujeito se constrói na relação com o outro. Se considerarmos, no caso da fala da professora AL, que ela também é professora, o uso da expressão "muitos alunos para um só professor atender" não diz respeito somente a um sujeito do passado sobre o qual ela se refere: diz respeito a uma familiaridade com a qual ela se depara no exercício da docência e também com a diversidade de sujeitos com os quais se interage em sala de aula. Tanto que ela chega a mencionar que não recorda o nome da disciplina, só lembra que o docente da época não tinha didática. O uso da expressão "Muitos alunos para um só professor atender" é uma espécie de confissão ou justificativa no sentido de apontar para algo incontornável: o ensino não chega para todos os discentes homogeneamente, pois há sempre lacunas, devido à presença de muitas singularidades de cada sujeito histórico, discursivo, conforme mencionado anteriormente.

Assim, ainda que ela apresente essa espécie de justificativa para a impotência do professor, há, também, o estabelecimento de um alerta: não houve (boa) didática e a aprendizagem foi insuficiente. É importante mencionar este posicionamento, porque, nos estudos bakhtinianos, o sujeito não é fonte do dizer e a subjetividade é construída na relação com o outro, conforme já se afirmou neste texto. Tal premissa aponta para o fato de que não se trata apenas de um enunciado isolado, mas de um enunciado que tem relação com outros enunciados, pois a professora $\mathrm{AL}$, enquanto sujeito discursivo, é um ser social.

Desse modo, a expressão “(não) tem didática” é reconhecida pelos seus pares, não porque se trata de um vocabulário específico, científico, mas porque é um argumento compartilhado entre professores e professoras no cotidiano escolar. Por isso, se utiliza, discursivamente, o método dialético-dialógico (PAULA; FIGUEIREDO; PAULA, 2011), pois o corpus está em frequente relação com outros enunciados "que respondem ou são respondidos no elo da cadeia discursiva" (PAULA; LUCIANO, 2020a, p. 708). É importante reiterar, também que, nos estudos bakhtinianos, é uma característica do enunciado que ele possa ser repetido. Mas isso não quer dizer que os efeitos dessa repetição sejam iguais, já que ocorrem regularidades, mas também dispersões de enunciados e de efeitos de sentidos. Tais instâncias remetem a circunstâncias sócio-histórico e politicamente específicas. Assim, a singularidade de cada enunciado - e sua repetição - não isenta de haver, na enunciação, marcações de discursos de outros sujeitos. O que ocorre é que a expressividade de 
determinado sujeito fica marcada no enunciado quando determinado sujeito enuncia por meio de uma intenção discursiva e horizonte ideológico específico ao direcionar-se a outrem (SILVEIRA; SANTANA, 2019).

Quando a professora AL afirma que "ele não tinha nenhuma didática (e vontade) para nos auxiliar" ela também debate (e se debate) responsivamente acerca dos enunciados que circulam nas relações sociais e na vida comum acerca do ato de tornar-se professor. Tal gesto produz um efeito de responsabilização do outro, que é valorado como sujeito negligente, "sem vontade de auxiliar". Ao nos voltarmos para a questão da pandemia, por exemplo, essa questão da vontade de auxiliar se torna importante. Nesse sentido, se considerarmos que a maioria das pessoas tem acesso à internet via uso de celular, muitas vezes compartilhado, perceber cada aluno como singular e com dificuldades inerentes à condição socioeconômica aponta para o fato de que a subjetividade dos professores e professoras é produzida na relação com a alteridade.

O verbo "auxiliar" está associado, ainda, à necessidade de adaptação, de incorporação de metodologias que auxiliem o outro. Torna-se não apenas um detalhe, pois a professora $\mathrm{AL}$ está falando de suas limitações enquanto discente e de um desconforto que parte de uma impressão coletiva, já que sua voz é perpassada por outros enunciados no elo da cadeia discursiva. Produz-se, assim, dialogicamente, não apenas uma afirmação sobre o outro, mas a indicação de um desconforto que pode apontar para uma vontade de não se caracterizar como "péssima”, da mesma forma como aquele que é valorado está sendo classificado no enunciado em questão. A sobrecarga de atividades docentes também é reiterada na expressão "para um só professor atender". Se aos professores que não estavam habituados e tinham dificuldades com o uso de tecnologias digitais em sala de aula há empecilhos, o excesso de estudantes corrobora a sensação de impotência. Somada à formação precária, então, se torna uma bola de neve.

Por outro lado, apesar de outro entrevistado, o professor AT, ter mencionado que não houve disciplina específica na graduação, ele também afirmou que o trabalho com tecnologias digitais foi resultado das atividades desenvolvidas: "A ferramenta AVA trazia atividades, materiais, links de PDFs, dentre outros, o que já nos habituou à dinâmica de uma ferramenta digital" (Professor AT, 2020). Vale destacar que AVA é uma sigla para Ambiente Virtual de Aprendizagem. A professora LM, sob o mesmo enfoque, menciona o uso do AVA, embora reconheça que "realizávamos algumas atividades esporádicas no AVA, alguns textos colaborativos, leituras, mas era muito pouco" (Professora LM, 2020, grifo nosso). 
Nesse caso, os excertos das respostas assinalados no parágrafo anterior apontam para a construção dos objetos de discurso: todo signo é ideológico porque está associado a valorações específicas no âmbito de determinado enunciado. Assim, o uso do verbo "habituar", no enunciado do professor AT, remete a uma valoração positiva das atividades desenvolvidas no entorno do AVA. Isso porque "habituar" traz um sentido de "tornar habitual, hábito, familiar". Nesse contexto, o uso da palavra "dinâmica", associada à ferramenta digital, acentua essa valoração positiva: dinâmica está para funcionamento assim como habitual está para familiaridade. Não apenas, portanto, se produz um efeito de familiaridade com instrumentos de interação digitais, há um movimento de positivação da experiência de formação inicial que tem aparição como se tivesse sido "suficiente". Diante disso, é importante assinalar que houve um efeito diferente produzido no enunciado da professora LM: há um efeito de negativação sobre o modo de funcionamento e de direção de atividades efetuadas por meio do AVA. Essa negativação corrobora o efeito de insuficiência, já que são utilizadas as expressões "esporádicas", ao se referir às atividades realizadas na graduação, e "era muito pouco". Assim, a organização do signo ideológico é necessária para a expressão do fato objetivo por meio da materialização desse signo (VOLÓCHINOV, 2017).

Já o professor JT, que cursou a graduação na modalidade semipresencial, afirma que "por ser na modalidade semipresencial, obtivemos treinamentos virtuais sobre como acessar e utilizar algumas plataformas digitais bastante usadas no campo educacional" (Professor JT, 2020, grifo nosso). É importante mencionar a questão da ideologia, nesse sentido, porque ela constitui a prática discursiva. O uso da palavra "treinamentos" pode produzir um efeito de seriedade e profissionalismo, mas, também, de homogeneização de aprendizagens, em virtude da ação de treinamento, no sentido de diminuir ou eliminar diferenças.

Em uma sala de aula considerada tradicional - com foco em perspectiva normativa e metodologia transmissiva unicamente, é comum que sejam reproduzidas atividades relacionadas à capacidade de ler e escrever que reduzem o ato de ler à decodificação de palavras e o ato de escrever à capacidade de codificar a língua no âmbito de uma forma visual do texto (GEE, 1996). Não é à toa que Lea e Street (1998) mencionaram a existência na escola daquilo que chamaram de modelo das habilidades. Aqui entra a questão do "treinamento", porque o modelo de habilidades está articulado à noção de letramento como conjunto de habilidades individuais e cognitivas, as quais, sob esssa lógica, precisam ser aprendidas. Tal modelo se volta para a tentativa de "corrigir" problemas de linguagem, de ordem gramatical, que podem ter aparição nos textos dos alunos. Lea e Street (1998) mencionam, então, que o aluno é visto a partir de seu déficit durante a correção de textos, já 
que se volta para o que ele não sabe, num contexto em que a escrita passa a ser vista como reflexo de habilidades técnicas e de intrumentalização do ensino da língua.

Nesse contexto, o resultado do "treinamento" é que ele desconsidera a trajetória anterior de letramentos do aluno e concentra esforços para que ele se adapte ao que precisa ser aprendido. Nesse escopo de considerações, é preciso salientar que não estamos defendendo que não haja necessidade de desenvolvimetnto de habilidades de leitura e de escrita específicas, mas que as capacidades já desenvolvidas precisam ser consideradas, a fim de viabilizar o entendimento acerca das condições de letramento dos discentes. Essa defesa se justifica porque, mais do que um recurso informacional, "as redes de aprendizagens instituídas na cultura digital, constituem uma forma de imersão e construção colaborativa de sentidos" (SÚNEGA; GUIMARÃES, 2017, p. 194).

A seguir, o professor referido anteriormente, informa que não se trata de qualquer plataforma digital, pois o sujeito discursivo menciona plataformas "bastante usadas no campo educacional". Nesse contexto, se no Círculo de Bakhtin a interação verbal é a realidade fundamental da língua, a viabilização do acesso e da utilizaçao de plataformas digitais está associada a modos de interagir em sociedade. Desse modo, a interação, que também está para além de instâncias verbais, realiza-se em ambientes verbivocovisuais ${ }^{7}$ e, assim, o acesso e a utilização de ambientes virtuais inserem sujeitos em ambientes que não são os ambientes e espaços físicos do cotidiano.

A professora $\mathrm{AX}$ respondeu que a formação com tecnologias digitais se deu "[n]a prática. E correndo atrás". Se a interação entre interlocutores é que funda a prática discursiva, podemos afirmar que há uma acusação de monologismo educacional: é como se a professora em questão afirmasse que não encontrou resposta na graduação (finalizada há dez anos), para que fosse suprida sua necessidade de trabalhar com tecnologias digitais. O que encontrou foi o vazio e o silêncio. Aqui é importanre mencionar que o discurso não produz a univocidade de um sentido tranquilizador. Ele pode apontar para caminhos diversos: nesse caso, na relação com outros enunciados pode produzir um sentido de de historicidade particular referente a um período determinado de sua história de vida, na qual os currículos dos cursos de licenciatura são caracterizados como insuficientes, a ponto de não dar suporte para o uso efetivo das tecnologias digitais. Este dizer também produz um efeito de positivação da ação alternativa

7 A pesquisadora (PAULA, 2017; PAULA; SERNI, 2017; PAULA; LUCIANO, 2020b) cunhou o termo verbivocovisual para se referir ao fato de que toda palavra é tridimensional, no âmbito dos estudos sobre sujeito e signo, por causa da inter-relação entre as dimensões verbal (semântica), vocal (sonora) e visual (imagética). 
empreendida, como se houvesse um autoelogio perante os desafios encontrados no caminho, que tornaram a formação insuficiente.

Outro detalhe é que o que não é respondido é preenchido pela presença do silêncio que significa. A professora $\mathrm{AX}$ não está falando de sua formação com tecnologias durante a licenciatura, mas de sua experiência cujas insuficiências formativas corroboraram o fato de que houve instâncias para as quais a formação inicial não a havia preparado. Então, no excerto assinalado no início do parágrafo anterior, ao invés de focar na formação, o enunciado é direcionado para a experiência pós-licenciatura. Assim, se faz mais do que caracterizar uma formação insuficiente - ainda que não se esteja falando diretamente da formação, mas de modo implícito - ela utiliza a expressão "correndo atrás". Como mencionamos mais de uma vez neste trabalho, todo signo é ideológico. Se é ideológico, então, a expressão "correndo atrás" produz um efeito de hierarquização entre o estágio associado à vivência do sujeito e o que se busca (ou buscou, no caso,) alcançar. A familiaridade com o uso de tecnologias digitais na escola se deu com o tempo porque o aprendizado sobre a utilização e acesso delas era, antes, insuficiente. Ao afirmar que a formação era insuficiente, o sujeito está valorando os processos formativos pelos quais passou, também como insuficientes. Mas "correndo atrás" não denota somente uma hierarquização, porque pressupõe uma necessidade. Não se "corre atrás" do que é desnecesário. Por isso, "correr atrás" está associado à palavra que lhe antecede: a prática (docente). Então, tem-se uma relação entre exigências e práticas necessárias no âmbito escolar.

A fim de demonstrar a inter-relação entre enunciados, podemos mencionar que a professora SD chegou a afirmar, por exemplo, que não teve "nenhuma disciplina voltada diretamente e exclusivamente ao uso de tecnologias" (Professora SD, 2020). No entanto, após o uso da conjunção adversativa "entretanto" ela menciona uma disciplina de Língua Inglesa na qual "tínhamos que propor slides, vídeos ou qualquer outra metodologia que envolvesse o uso da tecnologia". Aqui temos mobilizado o recurso de antecipação da resposta do interlocutor. Todo enunciado é responsivo porque pressupõe uma resposta (e até o silêncio é, nesse sentido, uma resposta). É preciso salientar que não defendemos, neste trabalho, que haja uma disciplina exclusiva para o uso de tecnologias, mas que as disciplinas estejam voltadas a dar suporte teórico-metodológico em cada contexto de ensino, visto que uma disciplina voltada "direta e exclusivamente" ao uso de tecnologias poderia correr o risco de se tornar um treinamento. Criticamos, então, a abordagem tecnicista que homogeneiza sujeitos, desconsiderando as trajetórias anteriores de letramento dos discentes. A essa altura, cabe reiterar que o conceito de dialogismo está associado ao de compreensão responsiva ativa. 
Assim, ao enunciar, o sujeito discursivo mobiliza experiências sociais e historicamente constituídas, demarcando uma posição e um juízo de valor sobre o interlocutor, tudo isso situado em determinada esfera de comunicação verbal (VOLÓCHINOV, 2017). Essa espera pela resposta é que produz esse efeito de antecipação do sujeito: daí a possibilidade de reformulação do enunciado da professora SD. "Nenhuma" e "exclusivamente" são palavras que caracterizam os subsídios ofertados na graduação para o uso de tecnologias. O que "exclusivamente" faz é especificar ressignificando o efeito de totalização que "nenhuma" havia produzido.

Desse modo, o que ela afirma é que não houve nenhuma disciplina que fosse voltada unicamente para o uso de tecnologias. Mas, depois disso, ela rememora uma disciplina de Língua Inglesa que, apesar de não ter sido centrada em tal uso, possibilitou observar e se apropriar de formas de utilização de "qualquer metodologia". Eis aí um exemplo de compreensão responsiva ativa porque quando falamos ou escrevemos consideramos o impacto das palavras sobre o interlocutor e o lugar ocupado por ele na esfera coletiva por meio da atenção para elementos como formação intelectual, grau de intimidade, posição social, por exemplo. Nesse contexto, a escolha do gênero do enunciado, as estratégias composicionais, os recursos linguísticos a ser utilizados são fatores que estão relacionados à necessidade de instauração da dialogicidade (LIMA; SANTOS, 2013).

A professora EG mencionou que não teve subsídios nem preparação para o trabalho com tecnologias digitais durante a graduação: "Não tive formação sobre isso em minha graduação". Em seu discurso, não houve a utilização da expressão "entretanto" para reiterar alguma experiência específica que destoasse da negação apresentada. Ainda assim, o enunciado também está associado a uma compreensão responsiva ativa, pois o interlocutor poderia indagar novamente sobre experiências mais particulares ou menores no âmbito da formação de licenciatura.

Mas a professora EG não está muito distante de muitos professores. Pesquisas como a de Camas (2013) e de Araújo (2010) já apontavam que é um desafio 'formar os futuros professores e os já atuantes na educação a entenderem e fazerem uso significativo das potencialidades tecnológicas na realização de suas aulas' (CAMAS, 2013, p. 186). Araújo (2010) mencionou que há receios e medos em relação às dificuldades que os professores sentem sobre a utilização de tecnologias da informação e comunicação. O estudo de Araújo chega a mencionar o ressentimento de professores acerca de condições precárias envoltas ao ensino, como [...] a ausência de um "técnico" para dar suporte, a formação precária e a ausência de projetos de formação continuada para utilização das tecnologias digitais, os receios e temores em aprender a manusear o computador, as resistências às novas tecnologias, a falta de projetos pedagógicos e o desconhecimento das 
possibilidades pedagógicas que envolvam o uso de tais tecnologias e, dentre outras, as condições precárias de acesso e conexão dos computadores à internet (ARAUJO, 2010, p. 3)

É preciso reiterar que as instituições formativas precisam considerar exigências e singularidades de cada professor em formação, considerando, também, o contexto das escolas e as particularidades do grupo que ali trabalha. Para Garcia (2010, p. 60), "não podemos pensar nos professores como um coletivo homogêneo, mas sim, que existem diferentes níveis de maturidade pessoal e profissional que os programas de formação de professores devem ter em consideração". O contato com diferentes artefatos e produções culturais, nesse âmbito, é importante para a ampliação de horizontes, que permitam o desenvolvimento de uma sensibilidade para questões particulares e tangenciais acerca do ato de situar-se como sujeito na contemporaneidade. Por isso que só a informação não abarca o todo da experiência educacional. Larrosa $(2002 ; 2003)$ menciona que a experiência está cada vez mais rara por causa do excesso de informação, do excesso de ocupação e da falta de tempo. Desse modo, para o autor, ao mesmo tempo em que se realiza um número cada vez mais abissal de atividades, e se adquire mais informações, pode nada transformar nos sujeitos, realçando a repetição e a reiteração dos receios e medos acerca das dificuldades de exercício da docência.

Recentemente, a pesquisa "Trabalho Docente em Tempos de Pandemia", realizada pelo Grupo de Estudos sobre Política Educacional e Trabalho Docente da UFMG, com apoio da Confederação Nacional dos Trabalhadores da Educação (CNTE), cujos dados foram coletados entre 08 e 30 de junho de 2020, com 15.654 docentes de todo o Brasil, oriundos da educação infantil, do ensino fundamental e da educação de jovens e adultos, concluiu que $82 \%$ dos professores estão lecionando de suas residências; $82 \%$ afirmaram que carga horária de trabalho aumentou; $84 \%$ mencionaram que o envolvimento dos discentes diminuiu um pouco ou vertiginosamente durante a pandemia. Sobre as principais dificuldades dos alunos, $80 \%$ afirmaram que a principal dificuldade dos alunos é o acesso à internet e a computadores, $74 \%$ que há dificuldade de terem apoio familiar para os estudos, 53\% mencionaram a falta de motivação dos alunos e 38\% afirmaram que os alunos têm desconhecimento em relação ao uso de recursos tecnológicos. Trata-se de uma situação singular com efeitos devastadores no aprendizado. Mas não são apenas os alunos os únicos afetados: 69\% dos professores declararam ter medo e insegurança por causa das incertezas sobre o retorno das aulas presenciais e, ainda, $50 \%$ têm medo em relação ao futuro.

As incertezas quanto à aprendizagem estão relacionadas, também, a outro problema: a inexperiência ou falta de familiaridade dos professores. É o que concluiu um levantamento 
elaborado pelo Instituto Península ${ }^{8}$ que foi realizado com 7.734 professores do Brasil entre os dias 13 de abril e 13 de maio de 2020. Nele, 83\%\% dos professores brasileiros não se sentem preparados para o ensino remoto e $88 \%$ revelam ter dado a primeira aula virtual na pandemia. Isso corrobora o fato de que boa parte dos professores teve - e tem - de se reinventar para aprender a lecionar de modo remoto, sem antes terem experimentado o formato online, de um modo, portanto, muito diferente do habitual.

Assim, o não uso ou falta de familiaridade com tecnologias digitais gera ainda mais dificuldades no ensino remoto, que se utiliza dessas tecnologias para propagar os processos de ensino-aprendizagem (MORAN; BEHRENS; MASSETO, 2006). Dessa forma, é preciso problematizar a práxis pedagógica transmissiva e unidirecional direcionando-se para a integração das novas tecnologias. Para Zajac (2020), o ensino remoto é uma adaptação improvisada da educação à distância por meio de ações como elaboração de materiais a ser utilizados pelos estudantes em casa, gravação de videoaula docentes ou transmissões online via plataformas virtuais como Google Meet, Classroom etc. As dificuldades que os professores têm sentido acerca do uso dessas plataformas estão associadas à necessidade de transformações nos modos de assimilar a didática ao ensino de qualidade no exercício de suas atividades.

Desse modo, se a resposta da professora EG aponta para a intercambialidade da constituição subjetiva: apesar de estar associada a outras professoras e professores que viveram em períodos históricos concomitantes (ela se formou faz mais de quinze anos), ela tem sua subjetividade construída quando negativiza sua formação. Isso porque as experiências são singulares e os modos de vida associados a instâncias de interação podem vir a ser outros, ainda que esta se aproxime daquela resposta inicial que apregoa que o professor não teve didática (aqui não houve didática nem disciplina formativa sobre tecnologias durante a graduação). Para que se possa notar um contraponto entre profissionais que tiveram formação via licenciatura presencial e à distância, a professora $\mathrm{KD}$, oriunda do segundo grupo, também não foi otimista em relação aos subsídios que recebeu. Ela menciona que:

[a]pesar da formação contemplar na disciplina de Didática, práticas digitais, não acredito que tenha sido bem trabalhado este tema para a formação do docente. Enquanto discente, trabalhamos muitos conteúdos digitais, visto que minha graduação foi à distância, porém, era voltado para o aluno, e não para o professor (Professora KD, 2020, grifo nosso).

${ }^{8}$ INSTITUTO PENÍNSULA. Sentimento e percepção dos professores brasileiros nos diferentes estágios do coronavírus no Brasil. Março 2020. Disponível em: https://institutopeninsula.org.br/wpcontent/uploads/2020/05/Pulso-Covid-19_-Instituto-Peni\%CC\%81nsula.pdf. Acesso em: 20 mar. 2021. 
O que chama atenção no enunciado é o uso da expressão "bem trabalhado" em relação ao tema em questão. Não ter sido "bem trabalhado" é algo que se difere, valorativamente, de não ter tido aparição nos processos formativos. Então, não é o caso de "nenhuma disciplina" ter se voltado para a questão das tecnologias digitais, como no início do enunciado da professora SD, apresentado anteriormente. O que ocorre, nesse caso, é que o sujeito caracteriza o trabalho formativo como insuficiente. Se pensarmos que todo enunciado concreto é responsável e responsivo, isso significa que somos sempre convocados a responder ativamente. Por isso, não existe neutralidade do discurso. Do mesmo modo, todo enunciado tem contato direto com a realidade (SILVEIRA; LOPES, 2018): o fato de ela haver mencionado que não foi bem trabalhada a questão do uso das tecnologias digitais remete a um objeto do mundo real: uma graduação que existe numa instituição determinada, cursada pelo sujeito que enuncia.

Pode ser destacado que, ao falar de formação, o sujeito não utiliza termos possessivos, como "minha formação" ou "nossa formação". A professora KD utiliza outro termo: "formação docente", no geral, o que aponta para um direcionamento acerca da importância de a formação ser "bem trabalhada"; essa formação não diz respeito somente a uma experiência particular: produz-se um efeito de generalização. Há uma regularidade sendo mencionada: segundo o enunciado, a formação docente pode ser ineficaz ou insuficiente no âmbito da educação à distância, o que pode gerar um estranhamento já que se as tecnologias são virtuais numa formação à distância, a lógica seria uma tendência a que houvesse um trabalho satisfatório de cunho formativo nesse âmbito específico. Então, por meio da responsividade ativa do enunciado, o sujeito discursivo enuncia que a formação online se dá a partir do enfoque no aluno e não no professor.

Mas tal abordagem se pauta, também, em questões tecnicistas, como se a apropriação das tecnologias digitais se suportasse por um treinamento no qual "fórmulas eficazes" são repassadas aos futuros professores, que deverão, harmoniosamente (sic), incorporá-las na sala de aula. No entanto, não se revela uma preocupação com o perigo de uma abordagem homogeneizadora, ou do seguimento de modelos únicos e acabados, a ser replicados em instâncias de escolarização. Há outra questão que precisa ser considerada: práticas pedagógicas estão articuladas a uma observação reflexiva e não à aplicação de metodologias “eficazes”. Quando a observação reflexiva está articulada à práxis, atividades são (re)elaboradas num professo de formação contínua. Isso porque as situações pelas quais os professores passam cotidianamente não podem ser diminuídas, porque os saberes vernaculares dos alunos precisam ser considerados e, assim, inevitavelmente, haverá necessidades de 
remanejo de atividades em sala de aula. Não somente se deve olhar para a formação docente como um locus de repetição e reiteração de saberes já aprendidos. Trata-se de um lugar que reflete e refrata um universo multifacetado marcado por questões tão diversas como desafios enfrentados pelos alunos na escola, falta de infraestrutura, conhecimento insuficiente de tecnologias digitais e, também, por problemáticas pedagógicas específicas de cada docente. Os enunciados, em consequência, estão sempre inter-relacionados na cadeia discursiva. Nesse contexto de explanações, pode ser notado, no exemplo a seguir, que outra entrevistada, que teve formação inicial de licenciatura a distância, apresentou, na resposta, um relato de experiência associado a impressões de dois cursos diferentes cursados num intervalo temporal amplo:

Concluí minha primeira graduação no ano de 2007, sendo esta de caráter presencial. Dado o periodo e também o formato do curso, a formação em relação ao uso de ferramentas digitais foi satisfatória. Utilizávamos programas, glossários online, dentre outras ferramentas. No entanto, foi possivel perceber uma importância muito maior para estes recursos ao realizar o curso de Letras, concluído no ano de 2017. Naturalmente, um curso realizado dez anos depois apresentaria diversas atualizações neste sentido, mas creio também ter bastante relação com o fato deste segundo curso ter sido realizado por meio de EAD (Professora CN, 2020, grifo nosso).

Se a professora KD havia mencionado que a educação a distância havia falhado no que diz respeito a uma formação de professores para o uso de tecnologias, a professora $\mathrm{CN}$ contrapõe, não necessariamente de modo consciente, a tese da docente anterior. Se a professora KD utilizou a expressão "não ter sido bem trabalhado" para afirmar como a formação havia sido insuficiente, a professora KD, por sua vez, utilizou a expressão "bastante relação" associada a uma valoração positiva da Ead. Inclusive, o enfoque do enunciado se dá na diferenciação entre o antigo e a novidade, onde um curso de graduação anterior, de cunho presencial, cuja conclusão foi em 2007, é visto como "suficiente" para a época. O que o sujeito discursivo faz é enunciar que sua formação já não tinha sido boa antes, e, com a graduação concluída em 2017, pode sentir "naturalmente" diversas atualizações. É importante trazer esse fragmento de enunciado, pois ele é o único que remete a experiências de uma formação híbrida, presencial e à distância.

O que nos chama atenção é o uso da expressão "naturalmente", como se houvesse um efeito de obviedade em relação à formação online quanto ao uso de tecnologias que levasse à obtenção de ferramentas para facultar, futuramente, a discentes tal uso. Enquanto que a professora $\mathrm{KD}$ associou a educação a distância a uma ineficiência, a professora $\mathrm{CN}$ 
associa tal modalidade de ensino superior a "diversas atualizações", mais do que suficientes, já que o curso presencial, finalizado em 2007, já teria lhe facultado habilidades para o trabalho com tecnologias digitais. Por que os dois enunciados $-\mathrm{o}$ anterior e este foram trazidos tão proximamente? Por que discursivamente não se trabalha com a noção de neutralidade do enunciado, mas a partir da existência de sujeitos intercambiáveis cuja singularidade não pode ser homogeneizada. A heterogeneidade, inclusive, é constitutiva da relaçao entre sujeitos em instâncias de interação social.

Finalmente, para mencionarmos outro exemplo, a professora LC apresentou argumentos pontuais relacionados o uso de sistema online de postagem de materiais pelos professores e, também, onde se dava "verificação de notas, financeiro e avisos diversos. Também tivemos aula sobre como utilizar a tecnologia para ministrar aulas" (Professora LC, 2020, grifo nosso). Essa professora direcionou o enunciado para um dos principais desafios da formação docente: como utilizar a tecnologia para ministrar aulas visando à aprendizagem dos estudantes. Assim, mais do que valorar positivamente sua formação, ela se difere de quem teve que "correr atrás", "aprender na prática”, por exemplo.

Desse modo, o enunciado produz um efeito de segurança, pois, ao direcioná-lo responsivamente, o sujeito discursivo em questão se diferencia de quem não teve formação suficiente. Mais do que valorar sua formação, tal enunciado está associado à necessidade de relacionar experiências do percurso discente com a tranposição temporal contemporânea na qual se assume o lugar da docência. No entanto, nesse caminho, outro percurso não pode ser ignorado: o das experiências discentes anteriores à formação escolar. Por isso, é preciso alertar para o fato de que aprender a utilizar a metodologia para determinado fim pode ser uma espécie de tecnicização, como se estivessemos no âmbito do treinamento mecânico de sujeitos.

É necessário, porém, ultrapassar esse espaço de ferramentalização para considerar experiências singulares dos sujeitos inseridos em práticas educacionais. Se antes, havíamos mencionado que a utilização de tecnologias digitais em sala de aula não pode ser só uma ferramenta, é porque acentuamos a necessidade de considerar as experiências de letramento dos estudantes ao invés de alijar diferenças e perpetuar homogeneizações no ensino. 


\section{Considerações finais}

Pensando no âmbito da reflexao e problematização da prática pedagógica, o fato de ter ou não a formação inicial, considerada suficiente, surte efeitos diretos no ensino remoto, sobretudo no contexto da pandemia em que estamos vivendo. Para que cada docente possa debruçar-se sobre sua prática, o reconhecimento das múltiplas situações de uso, da aticulação de conhecimentos prévios e de informações (extra) textuais em instâncias específicas é uma ação que pode produzir efeitos no cotidiano do ofício da docência (FISTAROL; FISCHER; BAILER, 2019). Nesse contexto, ao considerar excertos das falas dos entrevistados, conclui-se que os sujeitos discursivos são singulares, intercambiáveis e o enunciado concreto se articula a um ato responsável e responsivo, que reitera a inter-relação entre enunciados e o dialogismo das instâncias de interação verbal. Por isso, este texto não visou apresentar respostas definitivas, mas apreender, na interrelação entre enunciados, aspectos da formação inicial de sujeitos que hoje ocupam espaços de docência no Brasil. Mais do que abordar um retrato de uma história do presente, portanto, o que buscamos é assinalar que nenhum sujeito é substituível e que cada sujeito é atravessado por discursos e se constrói na relação responsiva e ativa com os demais.

\section{REFERÊNCIAS:}

ARAUJO, I. A. A. Formação de professores e tecnologias da informação e da comunicação: Professor, você tem medo de quê? Vertentes, São João Del-Rei, n. 35, p. 1-15, out. 2010.

BARROS, D. L. P. Contribuições de Bakhtin às teorias do discurso. In: BRAIT, B. (Org.). Bakhtin: dialogismo e construção de sentido. 2. ed. Campinas: editora da Unicamp, 2005. p. 25-36.

BARTHOLO, T. L. et al. O que as crianças sabem ao ingressarem na pré-escola na cidade do Rio de Janeiro? Ensaio: aval. pol. púb. educ., Rio de Janeiro, v. 28, n. 107, p. 292-313, 2020. DOI: http://dx.doi.org/10.1590/s0104-40362019002702071

COLEMAN, J. et al. Equality of educational opportunity. Washington: Government Printing Office, 1966.

FISTAROL, C. F. S.; FISCHER, A.; BAILER, C. Práticas de letramentos vernaculares em língua inglesa: a práxis na aprendizagem além do currículo formal da universidade. Revista Ibero-Americana de Estudos em Educação, Araraquara, v. 14, n. 4, p. 2358-2376, out./dez. 2019. DOI: https://doi.org/10.21723/riaee.v14i4.12719 
GARCIA, C. M. O professor iniciante, a prática pedagógica e o sentido da experiência. Revista Brasileira de Pesquisa sobre Formação Docente, Rio de Janeiro, v. 2, n. 3, p. 1149, ago./dez. 2010.

GEE, J. P. Social linguistics and literacies: ideology in Discourses. 2. ed. London/ Philadelphia: The Farmer Press, 1996.

GOIS, A. Incertezas, possibilidades e o que haverá de solido na educação depois da pandemia. In: NEVES, J. R. C (Org.). O mundo pós-pandemia. 2. ed. Rio de Janeiro: Nova Fronteira, 2020, p. 108-111.

HECKMAN, J. J. et al. The rate of return to the High Scope Perry Preschool Program. Journal of Public Economics, v. 94, n. 1-2, p. 114-128, fev. 2010.

IBGE. Instituto Brasileiro de Geografia e Estatística. Rio de Janeiro, 2020. Disponível em: https://cidades.ibge.gov.br/brasil/sc/blumenau/panorama. Acesso em 20 mar. 2021.

LARROSA, J. Notas sobre a experiência e o saber de experiência. Revista Brasileira de Educação, Rio de Janeiro, n. 19, p. 20-28. jan./abr. 2002. DOI: https://doi.org/10.1590/S1413-24782002000100003

LARROSA, J. Pedagogia profana: danças, piruetas e mascaradas. Belo Horizonte: Autêntica, 2003.

LEA, M.; STREET, B. Student Writing in higher education: an academic literacies approach. Studies in Higher Education, London, v. 23, n. 2, p. 157-16, June 1998.

LIMA, A. C. S.; SANTOS, L. F. Dialogismo e produções responsivas ativas: analisando práticas discursivas em aulas de língua portuguesa. Letras \& Letras, v. 29, n. 2, p. 1-11, 2013.

PAULA, L. de; SERNI, N. M. A vida na arte: a verbivocovisualidade do gênero filme musical. Raído, v. 11, n. 25, p. 178-201, jul. 2017.

PAULA, L. O enunciado verbivocovisual de animação - a valoração do "amor verdadeiro" Disney - uma análise de Frozen. In: FERNANDES JR., A.; STAFUZZA, G. B. (Org.). Discursividades Contemporâneas: política, corpo e diálogo. Campinas: Mercado de Letras, 2017. p. 287-314.

PAULA, L.; FIGUEIREDO, M. H.; PAULA, S. L. O Marxismo do/no Círculo. Slovo - o Círculo de Bakhtin no contexto dos estudos discursivos. Curitiba: Appris, 2011.

PAULA, L.; LUCIANO, J. A. R. Filosofia da linguagem bakhtiniana e sua tridimensionalidade verbivocovisual. Estudos Linguísticos, São Paulo v. 49, n. 2, p. 706-722, jun. 2020a.

PAULA, L.; LUCIANO, J. A. R. Filosofia da linguagem bakhtiniana: concepção verbivocovisual. Revista Diálogos (RevDia), v. 8, n. 3, p. 131-151, 2020 b. 
PNUD. Programa das Nação Unidas para o Desenvolvimento. Disponível em: https://www.br.undp.org/content/brazil/pt/home/. Acesso em: 27 mar. 2021.

RIBEIRO, V. M.; VÓVIO, C. L. Desigualdade escolar e vulnerabilidade social no território. Educar em Revista, Edição Especial, n. 2, p. 71-87, set. 2017.

SILVEIRA, É. L.; LOPES, L. R. Revisitando Bakhtin: notas sobre a lexicalidade entre palavras, (diálogo entre) discursos e a contribuição para os Estudos da Linguagem. In: SANTOS, E. S.; ALMEIDA, A. D.; NETO, N. A. S. Olhares sobre o léxico: perspectivas de estudo. Salvador: EDUNEB, 2018. p. 343-356.

SILVEIRA, É. L.; SANTANA, W. K. F. "Ele não" como ato de resistência: notas sobre Bakhtin, Foucault e a necessidade de dizer a verdade em atos responsáveis. In: FRANCELINO, P. F.; SANTANA, W. K. F. (Org.). Bakhtin e o Círculo em fronteiras do discurso. São Carlos: Pedro \& João, 2019, v. 1, p. 87-116.

SINTEX. Sindicato das indústrias de fiação, tecelagem e do vestuário de Blumenau. Economia diversificada e inovação se destacam para geração de empregos em Blumenau. Sintex, Blumenau, 06 set. 2028. Disponível em: http://www.sintex.org.br/noticia/2018/09/06/economia-diversificada-e-inovacao-se-destacampara-geracao-de-empregos-em-blumenau. Acesso em: 23 nov. 2020.

SÚNEGA, P. B. C.; GUIMARÃES, I. V. A docência e os desafios da cultura digital. Revista Reflexão e Ação, Santa Cruz do Sul, v. 25, n. 1, p. 178-197, jan./abr. 2017.

VOLÓCHINOV, V. (Círculo de Bakhtin). Marxismo e filosofia da linguagem. Problemas fundamentais do método sociológico na ciência da linguagem. Tradução, notas e glossário de Sheila Grillo e Ekaterina Vólkova Américo. Ensaio introdutório de Sheila Grillo. São Paulo: Editora 34, 2017.

\section{Como referenciar este artigo}

FISTAROL, C. F. S.; SILVEIRA, É L.; FISCHER, A. COVID-19 e uso de plataformas digitais: reverberações da sala de aula do espaço físico para o virtual. Rev. EntreLínguas, Araraquara, v. 7, n. 00, p. e021001, 2021. e-ISSN: 2447-3529. DOI: https://doi.org/10.29051/el.v7i00.15158

Submetido em: 20/03/2021

Revisões requeridas em: 26/04/2021

Aprovado em: 28/05/21

Publicado em: 01/06/2021 